\title{
Mathematical Model for Calculating Oxygen Mass Transfer Coefficient in Diffused Air Systems \\ Kossay K. Al-Ahmady, PhD,
}

\author{
University of Mosul, College of Engineering, Civil Engineering Department
}

\section{Abstract}

The key element in developing an analytical or mathematical procedure is to determine the main factors that possess potential importance in oxygen transfer process. In this paper, the factors that affect the oxygen mass transfer coefficient $\left(K_{L} a\right)$ in activated sludge units are determined. A dimensional analysis procedure is adopted to develop a mathematical model, which can be used for calculating these factors. A very high accurate model with a correlation factor of $(98.889 \%)$ is obtained from this analysis. The solution of the model shows that: The main dimensionless groups which controlling the oxygen mass transfer in this units are: Reynolds number, Froude number, the ratio of bubbles diameter to length of its bath in water, the ratio of water depth in the tank to tank length, and the ratio of diffusers area to tank area. Each of the Reynolds number and the ratio of area of diffusers to the area of tank have positive effect on the oxygen mass transfer coefficient. Increasing any of airflow rates, the area of diffusers coverage in the tank and the length of the path of bubbles in water significantly increase the oxygen mass flow rate while this ability can also be increased by decreasing the diameter of bubbles in the system.

Keywords: aeration, diffused air, oxygen transfer, dimensionless analysis, modeling

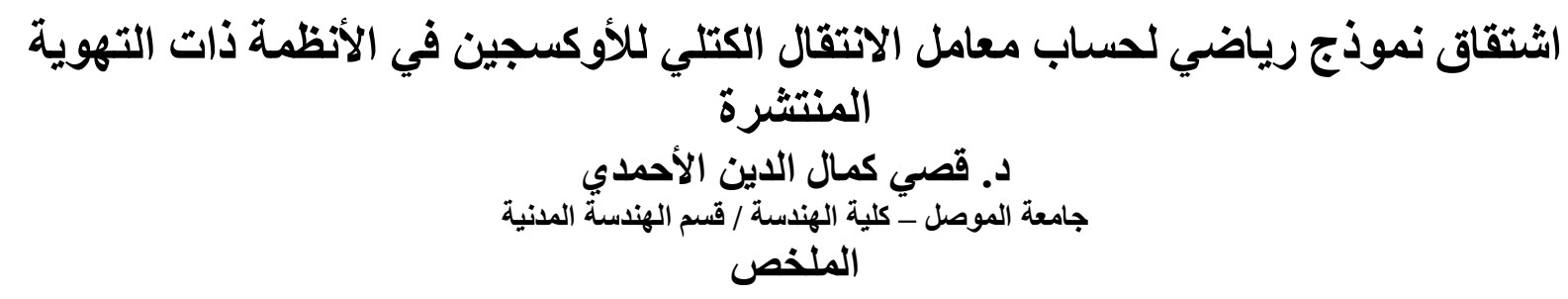

يعد تحديد العوامل المؤثرة على معامل انتقال الأوكسجين الحجمي في وحدات الحمأة المنشطة من أهم الخطوات

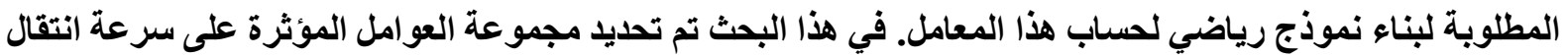

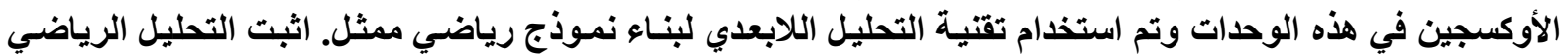

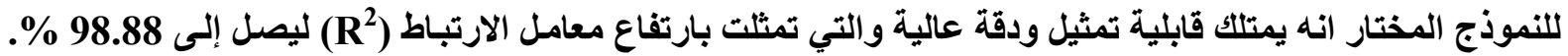

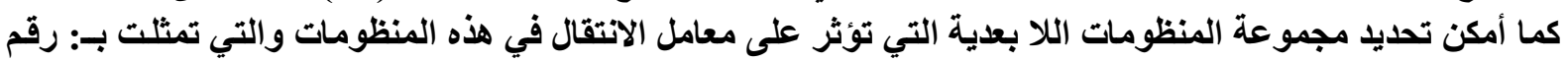

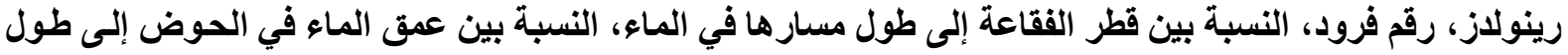

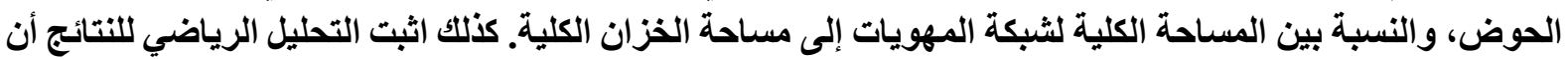

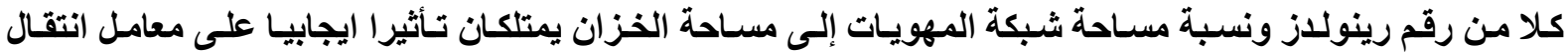

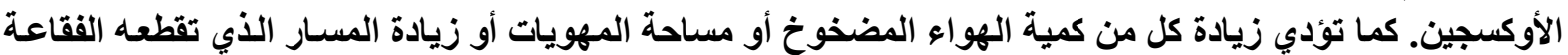
في الماء إلى رفع قيمة معامل الانتقال في حين يؤدي تقليل قطر الفقاعة الفي الى رفع قيمة هذا المعامل أيضا. 


\section{Introduction}

Diffused aeration systems are not only receiving increased theoretical attention but are also gaining a larger share of today's aeration market (EPA, 1989). This mode of aeration is selected for a variety of reasons including land availability, operation at high power levels with minimal surface spray and mist, and the ability to achieve high uptake rates with a large degree of process flexibility (WEF, 1996). These influences combined with the magnitude of the aeration market have provided the force for the development of numerous types of models, which used for the evaluation of these systems (EPA, 1989). The key element in developing an analytical or mathematical procedure is to determine the main factors that possess potential significant in oxygen transfer process. However, oxygen transfer in aeration tanks usually depends on certain hydrodynamic and physic-chemical factors (WEF, 1996). The process hydrodynamics are mainly dependent on the geometric characteristics of the system, such as tank length, width and depth, aeration type (fine pore, coarse bubble), size and locations; and the air feed rate (Metcalf and Eddy, 2004). Physic-chemical properties of the solution depend on the solution composition and temperature (AWWA, 2000).

The interaction of the factors given above leads to conclude that the efficiency of oxygen transfer can be assessed if the connections between the main factors are considered (Khudenko and Shpirt, 1986). Such relationships can be found by the use of the theory of similarity, e.g. dimensional analysis (Harremoes, 1979).

The dimensional analysis requires a previous understanding of all important parameters so that these parameters can be combined into dimensionless groupings of variables. This approach provides more readily to generalization than does the study of the influence of single parameters (Khudenko and Shpir, 1986). Additionally, the number of experiments needed to evaluate the relationships between complex dimensionless variables is fewer than that required for the evaluation of the effects of all parameters in various combinations (Harremoes, 1979).

In this paper, the dimensional analysis procedure was used to formulate an oxygen mass transfer coefficient function. The oxygen coefficient is related to the independent variables (geometry, dynamic and physic-chemical parameters) by the use of dimensionless similarity. The experimental data are generalized and used to solve the equation. The generalized equation together with other relationships mentioned can be used for the analysis and design of activated sludge diffused aeration systems.

\section{Previous studies}

(Molder, et al., 2009), studied the influence of alcohol molecules, as surfactants, on the oxygen mass transfer and bubbles surface tension in diffused aeration system. The experiments revealed that oxygen permeability was inhibited at very low surfactant concentrations, whereas a considerable increase in the surface tension was observed in a higher concentration range. (Chaumat, et al., 2006) investigated the bubbles hydrodynamics parameters of subsurface aeration systems. The result showed that there is a strong effect of liquid flow on both of axial and radial variations, bubble average diameter and frequency, and bubble surface area at low gas flow rate. On the contrary, liquid flow has limited effects at very high gas flow rates. (Adil, et al., 2006), explored the effect of surfactant on bubbles hydrodynamic and oxygen mass transfer at low Reynolds and Sherwood numbers. (Gamal and Smith, 2003), suggested a steady-state one-phase axial dispersion model to determine the overall mass transfer coefficient $\left(\mathrm{k}_{\mathrm{L}} \mathrm{a}\right)$ and liquid-phase axial dispersion coefficient $\left(\mathrm{D}_{\mathrm{L}}\right)$. The model has proven to be an accurate for describing the oxygenating process. (Tzeng, et al., 
2003), developed a dynamic mathematical model to simulate the oxygen transfer rate in activated sludge process. Simulations showed that, optimal control system was able to reduce aerator power compared to a conventional design. (Mingyan, 2003), investigated the chaotic bubbling mechanism in a gas-liquid bubble column. It was found that, the bubbling process exhibits a deterministic chaotic behavior in a certain range of the gas flow rate. When increasing the gas flow rate, the sequence of periodic bubbling, primary and advanced chaotic bubbling, and random bubbling were successively observed. (Chern and Yang, 2003), initiated a series of aeration studies to investigate the performance of the diffused aeration system. The experimental results showed that the volumetric mass-transfer coefficients increase with the airflow rate and temperature, but decrease with the water depth. The twozone model can satisfactorily predict the saturation DO concentrations and the volumetric oxygen transfer rates. (Rosso, et al., 2001), measured the oxygen transfer efficiencies for different types of diffusers at various depths and mean cell retention times. The results showed that aeration efficiencies are linearly related to depth of submergence, strongly influenced by mean cell retention times (MCRT). (Dold and Fairlamb, 2001), derived a mathematical model to describe the effect of airflow rate and diffuser density on the oxygen mass transfer coefficient in aerated activated sludge reactors. (Chern, et al., 2001), investigated the effects of the impurities on the oxygen transfer rate. The ASCE and the twozone oxygen mass-transfer models were used to analyze the unsteady state reaeration data. The results showed that the alpha factors based on the ASCE model are less sensitive to the impurity concentration while the presence of the impurities significantly reduces the alpha factors in the gas bubble zone.

\section{Oxygen Transfer}

Oxygen transfer is described by the value of mass transfer and the equilibrium concentration of oxygen in the liquid (Chaumat, et al., 2006). Most projects require a field oxygen transfer test to verify diffusers performance (Warriner and Brenner ${ }^{1}$ 1996). Oxygen transfer efficiency information can also be obtained by using laboratory apparatus (EPA, 1989). There are several experimental methods to determine mass transfer coefficient and the oxygen equilibrium concentration. Clean water mass transfer coefficient is usually determined by the non-steady state test procedure described in the standard methods (APHA, 2005). A second procedure involves a steady state test. Both techniques (steady and non steady state) produce acceptable results (EPA, 1989). The clean water non-steady state method is selected in this study.

\section{Non-steady state method}

For non-steady state testing, the average rate of oxygen accumulation in the liquid, $d c / d t$, can be described by the following equation:

$$
\frac{d C_{t}}{d t}=R_{0}=\left(K_{L} a\right)_{T} \cdot\left(C_{s t}-C_{t}\right)
$$

Where

$$
\left(K_{L} a\right)_{T}=\alpha \cdot \gamma \cdot\left(K_{L} a\right)_{20}
$$

$C_{s t}=$ the equilibrium concentration of oxygen in wastewater, $C_{t}=$ the oxygen concentration in the water at moment $\mathrm{t}, K_{L} a=$ the volumetric mass transfer coefficient, $\alpha=$ the admixtures correction factor and $\gamma=$ the temperature correction factor. The value of $\gamma$ is 
usually determined by empirical relationships of the form $\gamma=\theta^{T-20}$ where $\theta=1.024$ (ASCE, 1991; Boyle, et al., 1996; EPA, 1989; Metcalf and Eddy, 2004; WEF, 1996).

For the period of a given aeration run the value of the equilibrium concentration, $C_{s t}$ changes with the change oxygen concentrations. For small increments of $C_{t}$, which occur within short time intervals, $\Delta \mathrm{t}$, the value of $C_{s t}$ can be assumed to be constant (Khudenko and Shprit, 1973). Equation (1) can be solved as:

$$
\left(K_{L} a\right)_{T}=\frac{1}{\Delta t} \cdot \ln \frac{C_{s t}-C_{t}}{C_{s t}-C_{(t+\Delta t)}}
$$

In this equation, the value of $C_{s t}$ can be approximated by the following expression (Shifrin and Mishukov, 1972):

$$
C_{s t}=C_{s o} \cdot \frac{P_{a t m}+h / 2}{P_{a t m}} \cdot\left(1-\frac{\delta_{C}}{2}\right)
$$

$P_{\text {atm }}=$ atmospheric pressure (in meters $\mathrm{H}_{2} \mathrm{O}$ ); $h=$ submergence of diffusers; and $C_{s o}=$ the solubility of dissolved oxygen in water at normal atmospheric pressure. The term $\left(1-\delta_{c} / 2\right)$ accounts for the oxygen depletion from the air used for aeration. An alternative approaches which also account the oxygen depletion were discussed by other authors (ASCE, 1991, EPA, 1989, Metcalf and Eddy, 2004).

The fraction of oxygen transferred from air into water, $\delta_{c}$, can be found from the following relationship:

$\delta_{c}=$ rate of oxygen transfer / rate of oxygen supply

$$
=\frac{\left(K_{L} a\right)_{T}\left(C_{s t}-C_{t}\right) \cdot V}{q \cdot j}
$$

Where $V=$ aeration tank liquid volume; $q=$ total air flowrate; and $j=299$, i.e. the amount of oxygen in $\mathrm{g} / \mathrm{m}^{3}$ if air. Combining equations (4) and (5) yields:

$$
C_{s t}=\frac{\beta \cdot C_{s o}\left[1+\frac{\left(K_{L} a\right)_{T} \cdot C_{t} \cdot V}{2 \cdot q \cdot j}\right]}{\frac{P_{a t m}}{P_{a t m}+h / 2}+\frac{\left(K_{L} a\right)_{T} \cdot \beta \cdot C_{s o} \cdot V}{2 \cdot q \cdot j}}
$$

Equation (5) and (6) incorporate the effect of hydrodynamic and physic-chemical parameters on the equilibrium concentration of oxygen directly, as well as, through the value of the mass transfer coefficient, which also depends on hydrodynamic and physic-chemical parameters.

\section{Dimensional Analysis}

The main geometric and dynamic parameters of the diffused air system are shown in the figure 1. The physic-chemical parameters, which depend on the water temperature, are the viscosity of water, $\mu$, and the coefficient of molecular diffusion, $D$. The physic-chemical parameters also depend on concentration of admixtures, properties of the solids, bubble surface tension and other parameters (Molder, et al., 2009). However, most of these parameters are not measurable in mixed liquors (Groves, et al., 1992). In this paper, an 
empirical dimensionless $\alpha$ - factor is used to account all effects on the aerated water associated with admixtures. The $\alpha$ - factor is defined in equation (2).
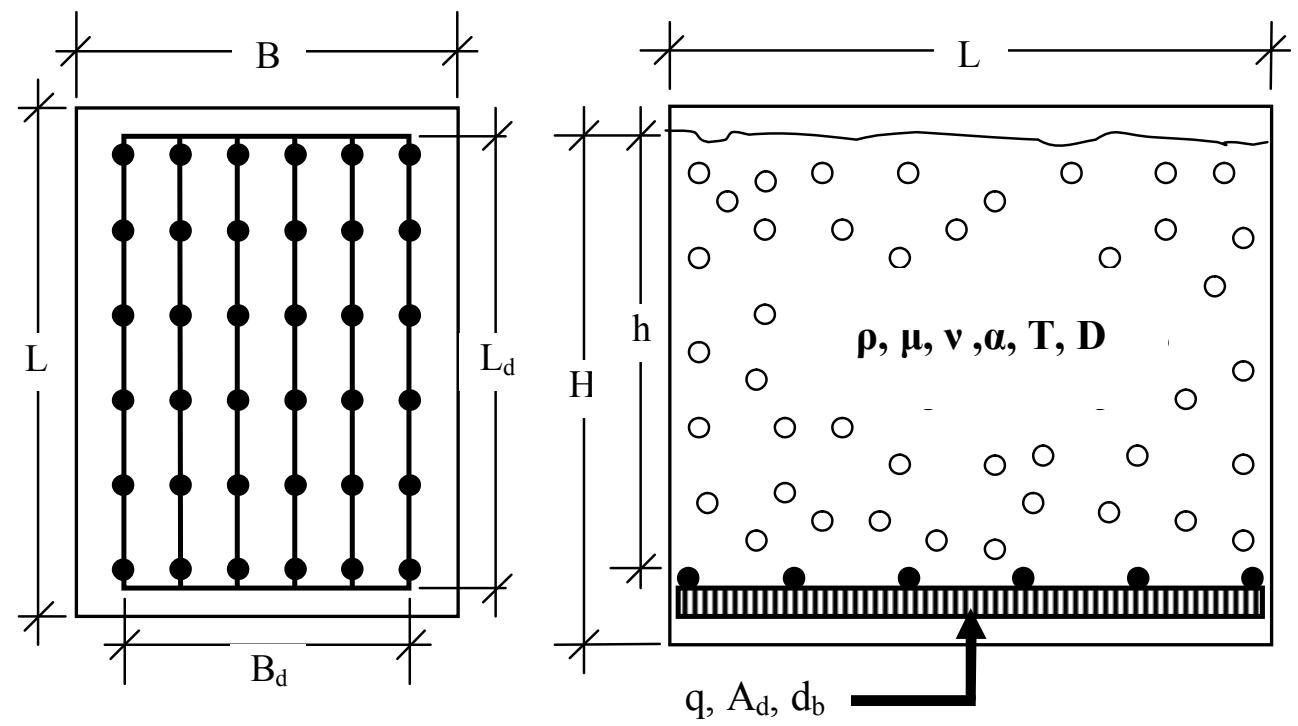

Fig. (1): General schematic diagram of the major parameters used in the model

Assuming that the mass transfer coefficient depends on the geometric and dynamic parameters the following expression can be written:

$$
K_{L} a=f\left(L, B, H, q, h, A_{d}, d_{b}, \alpha \cdot \gamma \cdot \rho, \mu, D, g\right)
$$

Where; $K_{L} a=$ volumetric mass transfer coefficient, $(1 / \mathrm{sec}),[1 / \mathrm{T}] ; L=$ length of the tank, (m), [L]; $B=$ width of the tank, (m), [L]; $H=$ height of water in the tank, (m), [L]; $q=$ total air flowrate, $\left(\mathrm{m}^{3} / \mathrm{sec}\right),\left[\mathrm{L}^{3} / \mathrm{T}\right] ; h=$ submergence of diffusers, $(\mathrm{m}),[\mathrm{L}] ; A_{d}=$ the total area of the diffusers, $\left(\mathrm{m}^{2}\right),\left[\mathrm{L}^{2}\right] ; d_{b}=$ average diameter of bubbles, $(\mathrm{m}),[\mathrm{L}] ; \rho=$ density of water, $\left(\mathrm{kg} / \mathrm{m}^{3}\right),\left[\mathrm{M} / \mathrm{L}^{3}\right] ; \mu=$ viscosity of water, $(\mathrm{kg} / \mathrm{m}$. sec), $[\mathrm{M} / \mathrm{LT}] ;$ and $D=$ coefficient of molecular diffusion, $\left(\mathrm{m}^{2} / \mathrm{sec}\right),\left[\mathrm{L}^{2} / \mathrm{T}\right]$.

The admixture correction factor, $\alpha$, and temperature correction factor, $\gamma$, can be deleted from the model since they are already included in equation (2), the values of $D, \rho$ and $\mu$ can be treated as constants (Khudenko and Shpir, 1986). By grouping physical and geometric parameters, one can compose a critical equation which, in accordance with the $\pi-$ theorem, and considering, $L$, as repeating variable, the following dimensionless complexes will be achieved:

$N_{s h}=\phi \cdot \operatorname{Re}^{\phi 1} \cdot N_{F r}^{\phi 2} \cdot\left(\frac{d_{b}}{h}\right)^{\phi 3} \cdot\left(\frac{H}{L}\right)^{\phi 4} \cdot\left(\frac{A_{d}}{A_{t}}\right)^{\phi 5}$

Where,

$\phi, \phi_{1}-\phi_{5}=$ constants, from the solution of the equation;

$N_{s h}=\frac{L^{2} \cdot K_{L} a}{D}=$ Sherwood number;

$\operatorname{Re}=\frac{q \cdot \rho}{L \cdot \mu}=$ Reynolds number; 
$N_{F r}=\frac{Q}{\sqrt{L^{5} \cdot g}}=$ Froude number;

$A_{d}=$ the total area of diffusers $=\left(L_{d} \times B_{d}\right)$;

$\mathrm{A}_{\mathrm{t}}=$ the total area of the tank $=(\mathrm{L} \times \mathrm{B})$.

These dimensionless complexes reflect the geometric, kinematic and physic-chemical similarity of aeration systems. Physically, the Sherwood number relates the rate of turbulent mass transfer to the rate molecular diffusion, the Reynolds number represents the ratio of internal forces initiated by air bubbles to friction forces determined by the viscosity of water, and the Froude number relates the specific kinetic energy associated with the upwardly moving aerated volume of water to the specific potential energy of a water column of the same depth as the aerated volume (Khudenko and Shprit, 1986).

The ratio $\left(d_{b} / h\right)$ in equation $(8)$ represents the effect of the aerator location in the tank related to the bubble size. The ratio of $(H / L)$ represents the effect of shape and the tank geometry on equation (8). The ratio of $\left(A_{d} / A_{t}\right)$ represents the effect of the total area of the diffusers with respect to the area of the tank.

For convenient computation of the mass transfer coefficient values, equation (8) can be transformed into the following design formula:

$$
K_{L} a=\frac{\phi}{L^{2}} \cdot \operatorname{Re}^{\phi 1} \cdot F r^{\phi 2} \cdot\left(\frac{d_{b}}{h}\right)^{\phi 3} \cdot\left(\frac{H}{L}\right)^{\phi 4} \cdot\left(\frac{A_{d}}{A_{t}}\right)^{\phi 5}
$$

\section{Material and Methods}

The objective of the experimental work was to determine the constant $\phi$ and the exponents $\phi_{1}-\phi_{5}$ in equation (9). The experiments were carried out in two different tanks of sizes $(0.55 \mathrm{~m} \times 0.35 \mathrm{~m} \times 0.38 \mathrm{~m})$ and $(0.5 \mathrm{~m} \times 1.0 \mathrm{~m} \times 1.0 \mathrm{~m})$, (Length $\times$ Width $\times$ Depth). Within the tanks, the diffusers were placed closely to the bottom in that arrangement so that the longitudinal placement of diffusers was achieved. The oxygen transfer tests were conducted with a batch mode of operation, using potable water obtained from the distribution system. Prior to each group of assays, the tanks were drained, cleaned and filled with clean water to avoid salt accumulation (Richard, et al., 1974). Each run at a given parameters consisted of: DO depletion with sodium sulfite in the presence of a cobalt catalyst, measurement of DO concentration versus time of aeration, and determination of water temperature and air pressure.

The total amount of $\left(\mathrm{Na}_{2} \mathrm{SO}_{3}\right)$ required per assay was calculated theoretically depending on the initial concentration of dissolved oxygen in the test water (ASCE, 1991). The sodium sulfite $\left(\mathrm{Na}_{2} \mathrm{SO}_{3}\right)$ was added to the tanks as a slurry. $10-30 \%$ excess sodium sulfite was used each assay (Metcalf and Eddy, 2004). The sodium sulfite was maintained in suspension by mixing. $\mathrm{CoCl}_{2} \cdot 6 \mathrm{H}_{2} \mathrm{O}$ was added to the tank at the beginning of each test. Sufficient cobalt chloride is added to provide a minimum $\mathrm{Co}^{+2}$ concentration of $1.5 \mathrm{ppm}$ (Richard, et al., 1974).

The dissolved oxygen concentrations of the samples were determined using a dissolved oxygen meter type (EXTECH 407510) with magnetic stirrer. The probe was calibrated immediately before and after each run, using modified Winkler dissolved oxygen titration procedure (APHA, 2005). Periodic calibration checks were made during the run using distilled water samples of known DO concentration. Dissolved oxygen determinations were performed on samples collected at a point located nearby the side of basin. Due to the 
small size of the basin, one sample location was assumed to be representative the total basin volume (EPA, 1989). In some runs, the readings were conducted with another positions but no difference was noted. The air flowrate was measured with a pre-calibrated cage. Water temperature was measured before and after each test, and the average values were used in the data analysis. It was not possible to conduct all tests at $20^{\circ} \mathrm{C}$ as has been recommended (Metcalf and Eddy, 2004); therefore, the values of $\mathrm{K}_{\mathrm{L}}$ a obtained had to be adjusted to the standard temperature of $20^{\circ} \mathrm{C}$ according to the standard equation (ASCE, 1991; Boyle, et al., 1996; EPA, 1989; WEF, 1996).

The major shortage in this test is that it is carried out in small scale so, the results mainly limits by the test circumstances. Accordingly, in this study number of points from published articles were also collected (Boyle, et al., 1996; Lioyed, et al., 1979; Khudenko and Shprit, 1973; Khudenko and Shprit, 1986, Michael and Ronald, 1979; Muller and Boyle, 1988; Richard, et al., 1974; Shifrin and Mishukov, 1972; Suschka, 1971, Warriner and Brenner $^{1}$, 1996; Warriner and Brenner ${ }^{2}$, 1996). The points were selected from plants which have a scale larger than this which adopted by the experimental work. After sorting out, all data were treated and combined with the experimental points in order to expand the applicability of the results. In table (1), the ranges of the values of the selected parameters used in the calculation were presented.

Table (1): Ranges of values of the parameters used in the solution of equation (9). (Boyle, et al., 1996; Lioyed, et al., 1979; Khudenko and Shprit, 1973; Khudenko and Shprit, 1986, Michael and Ronald, 1979; Muller and Boyle, 1988; Richard, et al., 1974; Shifrin and Mishukov, 1972; Suschka, 1971, Warriner and Brenner $^{1}$, 1996; Warriner and Brenner ${ }^{2}, 1996$ )

\begin{tabular}{|c|c|c|c|}
\hline & Parameter & Unit & Range \\
\hline 1 & Length of tank ( L ) & $\mathrm{m}$ & $2.50-10.46$ \\
\hline 2 & Width of tank ( B ) & $\mathrm{m}$ & $1.00-2.83$ \\
\hline 3 & Depth of water, ( H ) & $\mathrm{m}$ & $1.50-7.01$ \\
\hline 4 & Submergence of aerator, $(\mathrm{h})$ & $\mathrm{m}$ & $0.45-6.40$ \\
\hline 5 & Air discharge by area of tank ( I ) & $\mathrm{m}^{3}$ air $/ \mathrm{m}^{2} \operatorname{tank} . \mathrm{hr}$ & $5.12-114$ \\
\hline 6 & Air discharge, ( Q ) & $\mathrm{m}^{3} / \mathrm{hr}$ & $26.0-737.064$ \\
\hline 7 & Width of diffusers / Width of tank, $\left(\mathrm{W}_{\mathrm{d}}\right.$ / B) & $\mathrm{m} / \mathrm{m}$ & $0.25-0.98$ \\
\hline 8 & Submergence / Depth of water $(\mathrm{h} / \mathrm{H})$ & $\mathrm{m} / \mathrm{m}$ & $0.118-0.964$ \\
\hline 9 & Volumetric mass transfer coefficient, $\left(\mathrm{K}_{\mathrm{L}} \mathrm{a}\right)$ & $\min ^{-1}$ & $0.036-1.77$ \\
\hline 10 & Average diameter of bubbles, $\left(d_{b}\right)$ & $\mathrm{m}$ & $0.0025-0.011$ \\
\hline 11 & Depth of water / length of tank, (H/L) & $\mathrm{m} / \mathrm{m}$ & $0.378-1.201$ \\
\hline 12 & total area of diffusers / area of tank, $\left(\mathrm{A}_{\mathrm{d}} / \mathrm{A}_{\mathrm{t}}\right)$ & $\mathrm{m}^{2} / \mathrm{m}^{2}$ & $0.10-0.897$ \\
\hline 13 & Sherwood number, $\left(L^{2} \times K_{L} a / D\right)$ & $\left(\mathrm{m}^{2} / \mathrm{sec}\right) /\left(\mathrm{m}^{2} / \mathrm{sec}\right)$ & $0.0131-0.938$ \\
\hline 14 & Reynolds number, $(Q \times \rho) / L \times \mu)$ & $(\mathrm{kg} / \mathrm{sec}) /(\mathrm{kg} / \mathrm{sec})$ & $0.0075-0.3588$ \\
\hline
\end{tabular}




\section{Generalization and Solution of the Model}

All the derivatives in equation (9) were calculated numerically using Nonlinear Regression Summary Statistics (SPSS) program. The general solution of the model is as follow:

$$
K_{L} a=\frac{0.03254}{L^{2}} \cdot \operatorname{Re}^{1.4647} \cdot F^{-0.4857} \cdot\left(\frac{d_{b}}{h}\right)^{-0.7261} \cdot\left(\frac{H}{L}\right)^{-1.7685} \cdot\left(\frac{A_{d}}{A_{t}}\right)^{0.2368}
$$

In table (2), the output of the statistical solution of the model is presented. In figure (2), the correlation between experimental values of $\mathrm{K}_{\mathrm{L}}$ a and values computed from equation (10) is illustrated. As noted table (2) and figure (2), the fitness of the model is very high. The value of the coefficient of correlation $\left(\mathrm{R}^{2}\right)$ is equal to $(98.88 \%)$. Most of the experimental points are conforming to their corresponding calculated points.

Table (2): Statistical outputs of the solution of the equation (10)

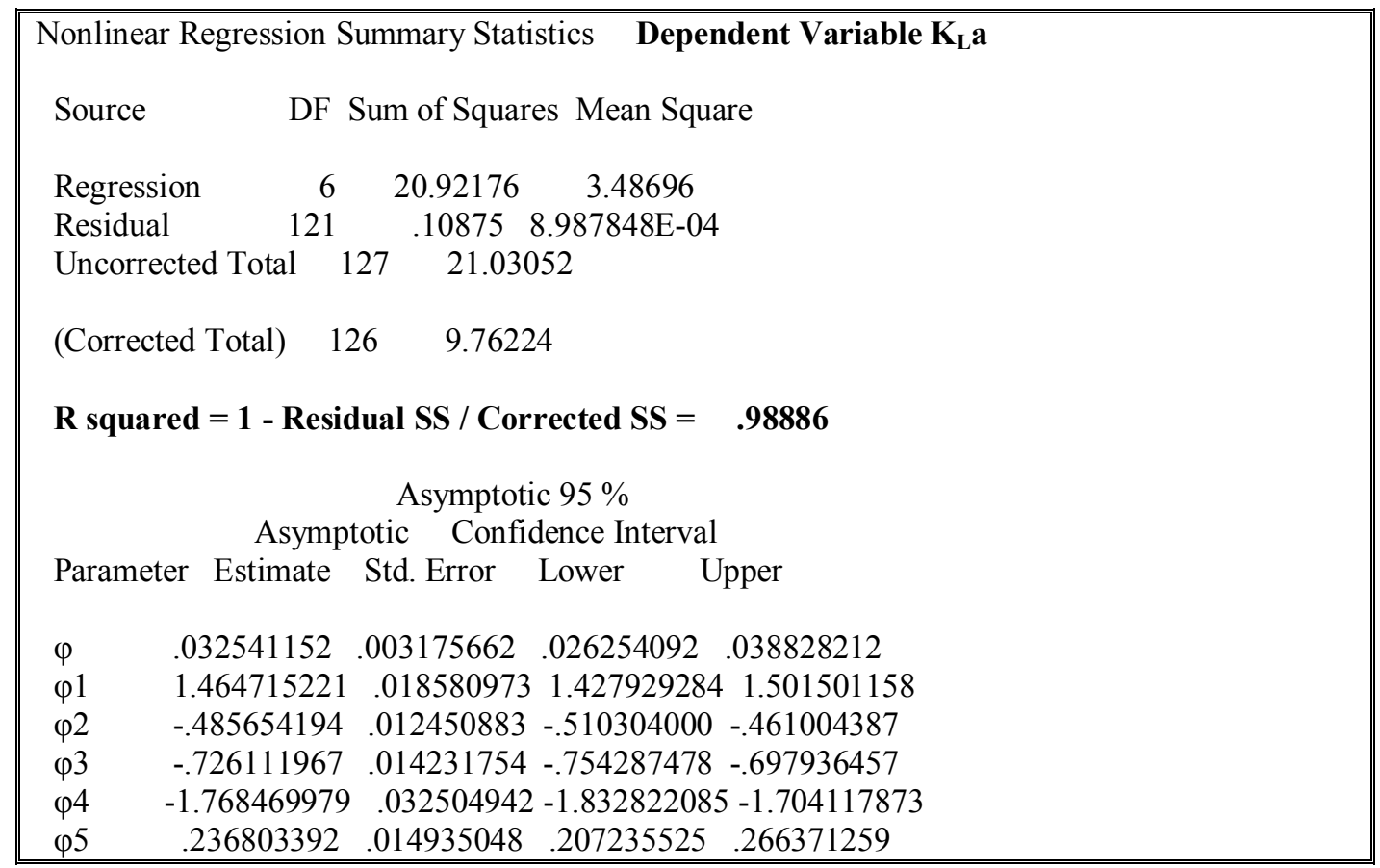

\section{Effect of Major Parameters on the Oxygen Mass Transfer Coefficient}

The effect of Reynolds number on the mass transfer coefficient $\left(\mathrm{K}_{\mathrm{L}} \mathrm{a}\right)$ is illustrated in figure (3) for two different diameters of coarse bubbles. As noted in the figure, at a given type of diffuser, the mass transfer coefficient is directly proportional to the Reynolds number. This result is in a good agreement with equation (10). Since the parameters, $(\mathrm{L}, \rho$, and $\mu$ ) are constant within the specified system, Reynolds number directly represents the effect of air flow rate on the system.

However, increasing air flowrate influences on the oxygen mass transfer rate by means of three ways; (1) boosts the bubbles density in solution and accordingly increases the contact surface area between the bubbles and water; (2) increases bubbles breaking up procedure due to improve agitation degree of the system; (3) extends bubbles residence time in the tank as the current patterns developed force bubbles to take longer paths to the surface. 
Many researchers (AWWA, 2000; Boyle, et al., 1996; Chern and Yang, 2003; Groves, et al., 1992; Metcalf and Eddy, 2004; Paul, 2001) signed to the positive effect of airflow rate on the mass transfer coefficient $\left(\mathrm{K}_{\mathrm{L}} \mathrm{a}\right)$.

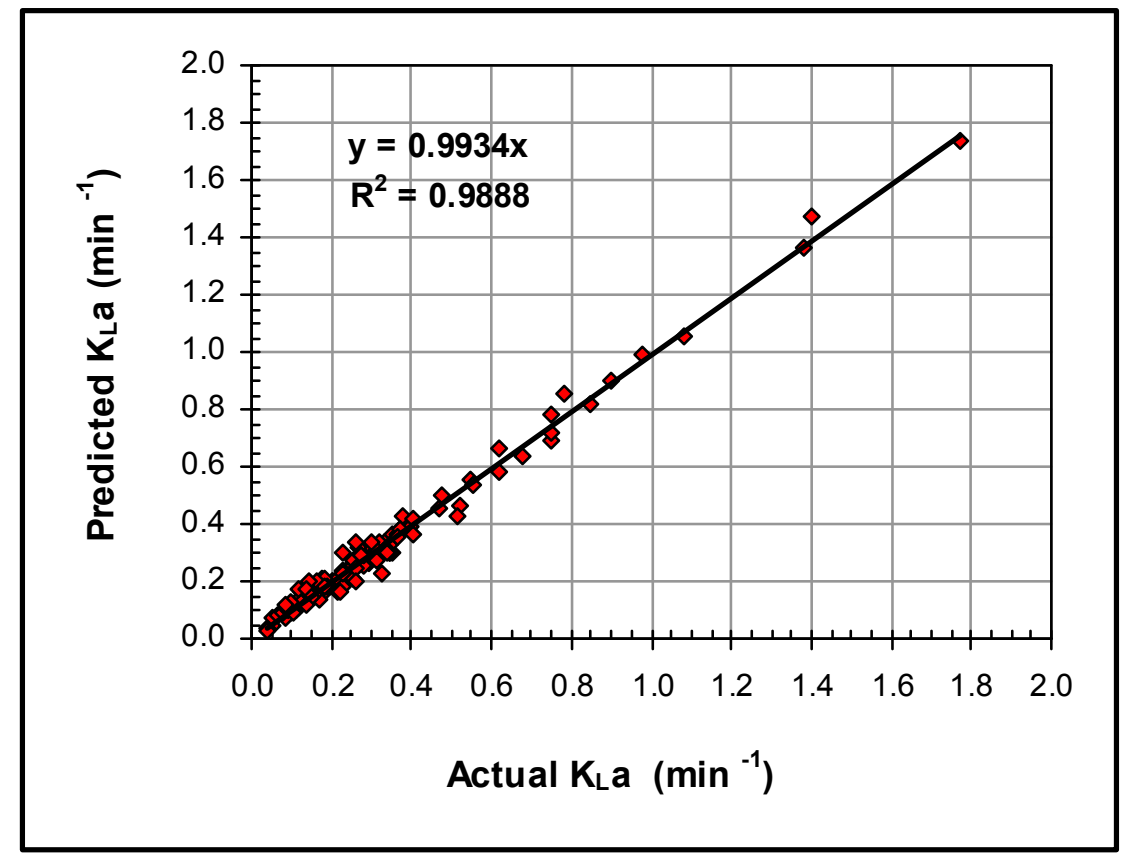

Fig. (2): Correlation of experimental and calculated values of the oxygen mass transfer coefficient, $\left(K_{L} \mathbf{a}\right)$

In figure (3), the effect of $\left(\mathrm{d}_{\mathrm{b}} / \mathrm{h}\right)$ ratio on the mass transfer coefficient $\left(\mathrm{K}_{\mathrm{L}} \mathrm{a}\right)$ is presented. As noted, at given air flowrate, Froude number, $H / L$ and $A_{d} / A_{t}$ ratios, smaller $\left(d_{b} / h\right)$ value gives larger mass transfer coefficient. As understood, lesser ratio obtained by either increasing the diffusers submergence or decreasing the bubbles diameters. Each of these parameters has positive effect on the mass transfer coefficient. Higher diffusers submergence leads to longer bubbles pathway inside the tank whereas; finer bubbles diameter expands contact surface area between the bubbles and water.

In figure (4), the effect of Reynolds number on the mass transfer coefficient $\left(\mathrm{K}_{\mathrm{L}} \mathrm{a}\right)$ at different $\left(A_{d} / A_{t}\right)$ ratios was presented. As noted, at given air flowrate, Froude number, $d_{b} / h$ and $H / L$ ratios, increasing $\left(A_{d} / A_{t}\right)$ ratio, i.e., diffusers coverage area, increases mass transfer coefficient. The maximum effect obtained when this ratio closes to (1.0), i.e., diffusers cover most floor of the tank. Larger diffusers coverage area produces better bubbles distribution in water and consequently produces larger gas-liquid surface area higher aeration efficiency. This result agreement with that recorded by other researchers (Dold and Fairlamb, 2001, EPA, 1989) and with equation (10) as the exponent of $\left(A_{d} / A_{t}\right)\left(\varphi_{5}\right)$ has a positive value.

The negative exponents $\left(\varphi_{3}\right.$ and $\left.\varphi_{4}\right)$ in equation (10) leads to conclude that, from the oxygen transfer standpoint, it is more suitable to construct a tank with smaller (H/L) ratio and higher diffusers submergence. Similar result also recorded by other researchers (Chern and Yang, 2003; Metcalf and Eddy, 2004; Rosso, et al., 2001) 


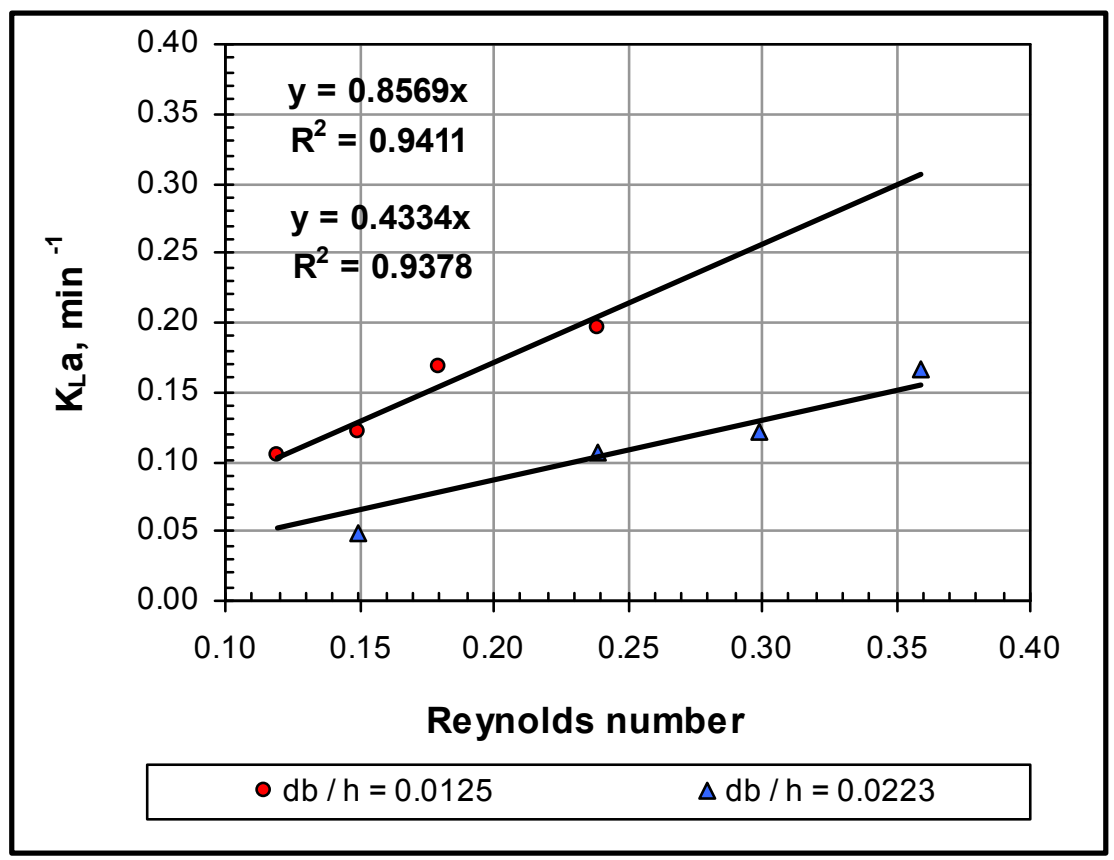

Fig. (3): Effect of Reynolds number on the oxygen mass transfer coefficient, $K_{L} a$, at constant: (Froude number, $\mathrm{H} / \mathrm{L}$ and $\mathrm{A}_{\mathrm{d}} / \mathrm{A}_{\mathrm{t}}$ ). (Coarse bubbles)

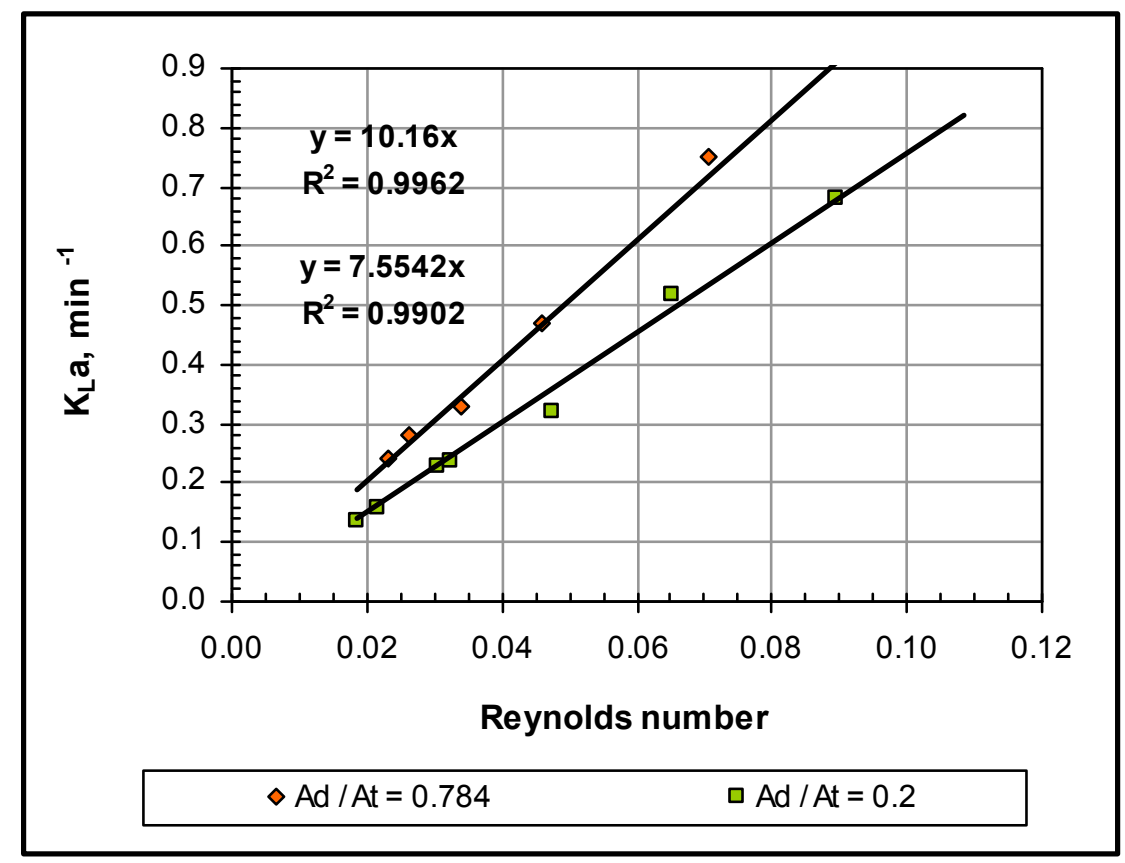

Fig. (4): Effect of Reynolds number on the oxygen mass transfer coefficient, $K_{L} a$, at constant: (Froude number, $d_{b} / h$ and, $\left.H / L\right)$. (Fine bubbles) 


\section{Conclusions}

1. Oxygen mass transfer coefficient $\left(\mathrm{K}_{\mathrm{L}} \mathrm{a}\right)$ in activated sludge systems can be effectively represented using the dimensional analysis technique. This result could be approved by the high correlation factor of the developed model.

2. Each of the Reynolds number and $\left(\mathrm{A}_{d} / \mathrm{A}_{t}\right)$ ratio have positive effect on the oxygen mass transfer coefficient. This effect could be represented by the positive values of the corresponding exponents in the model.

3. Increasing airflow rates, diffusers coverage area and diffusers submergence significantly increase the oxygen mass transfer coefficient while increasing Froude number, $(\mathrm{H} / \mathrm{L})$ ratio and bubbles diameter adversely influence on this coefficient.

\section{References}

Adil Dani; Arnaud Cockx; Pascal Guiraud, (2006), "Direct Numerical Simulation of Mass Transfer from Spherical Bubbles: the Effect of Interface Contamination at Low Reynolds Numbers", International Journal of Chemical Reactor Engineering, Vol. 4, Article A2.

American Society of Civil Engineering (ASCE), (1991) "Wastewater Treatment Plant Design" WPCF Manual of Practice No. 8, ASCE Manual on Engineering Practice No. 36, Lancaster Press, Inc. Lancaster, Pa., USA, $3^{\text {rd }}$ edition, Chapter 14, (Activated Sludge).

American Water Works Association (AWWA), (2000), "Water Quality and Treatment" A Handbook of Community Water Supplies, McGraw-Hill Handbooks, USA, Fifth edition, Chapter 5, (Air Stripping and Aeration).

APHA, AWWA, WEF, (2005), "Standard Methods for Examination of Water and Wastewater", $21^{\text {st }}$ ed., American Public Health Association, American water work association, water Environment Federation, Baltimore, Maryland.

Boyle W. C.; Craven A.; Danely W.; Riech M., (1996) "Oxygen Transfer Studies at the Madison Metropolitan Sewerage District Facilities" Risk Reduction Engineering Laboratory, Office of research and Division, US EPA, Cincinnati, Ohio, 45268.

Chaumat, Helene; Billet, Anne-Marie; Delmas Henri, (2006), "Axial and Radial Investigation of Hydrodynamics in a Bubble Column; Influence of Fluids Flow Rates and Sparger Type", International Journal of Chemical Reactor Engineering, Vol. 4, Article A25.

Chern, Jia-Ming; Yang, Sheng-Ping, (2003), " Oxygen Transfer Rate in a Coarse-Bubble Diffused Aeration Systems", Ind. Eng. Chem. Res., 42 (25), pp 6653-6660

Chern, Jia-Ming; Chou, Shun-Ren; Shang, Chou-Sheng, (2001), "Effects of Impurities on Oxygen Transfer Rates In Diffused Aeration Systems", Water Research, Volume 35, Issue 13, pp. 3041-3048.

Dold, Peter; Fairlamb, Mark, (2001), "Estimating Oxygen Transfer $\mathrm{K}_{\mathrm{L}} \mathrm{a}$, SOTE and Air Flow Requirements In Fine Bubble Diffused Air Systems", Water Environment Federation, WEFTEQ.

Environmental Protection Agency (EPA), (1989), "Design Manual: Fine Pore Aeration Systems" Risk Reduction Engineering Laboratory, Center of Research and Development, US. EPA, Cincinnati, Ohio, 45268.

Gamal El-Din M.; Smith, D.W., (2003), "Mass transfer analysis in ozone bubble columns", Journal of Environmental Engineering and Science, Vol. 2, pp. 63-76.

Groves K.P. et al, (1992), "Evaluation of Oxygen Transfer Efficiency and Alpha Factor on a Variety of Diffused Aeration Systems", Water Environmental Research, 64, (5).

Harremoes, P., (1979), "Dimensionless analysis of circulation, mixing and oxygenation in aeration tanks", Prog. Water Technology, 11. 
Khudenko B. M.; Shprit E. A., (1973), "Wastewater Aeration", Publishing House Stroyizdat, Moscow, (In Russian).

Khudenko B.M.; Shpirt E., (1986), "Hydrodynamic Parameters of Diffused Air Systems" Water Research, 20 (7).

Lioyed E; David T.R; Jermo D. W., (1979), "Testing and Data Analysis of Diffused Aeration Equipment", J. Water Pollution Control Fed., 51 (10).

Metcalf and Eddy, (2004), "Wastewater Engineering" $4^{\text {th }}$ edition, McGraw Hill Companies, International Edition, Singapor.

Michael B. L. and Ronald N. S., (1979), "Subsurface Aeration Evaluation", J. Water Pollution Control Fed., 51 (10).

Mingyan Liu, (2003), "Nonlinear Bubbling Hydrodynamics in a Gas-Liquid Bubble Column with a Single Nozzle", International Journal of Chemical Reactor Engineering, Vol. 1, Article A32.

Molder, Erik; Tenn Taavo; Tenno Toomas, (2009), "Research of Oxygen Mass Transfer Through The Air-Water Surface at Low Bulk Concentrations of Surfactants", Proceedings of the Estonian Academy of Sciences, 58, 2, pp.132-136.

Muller J.A.; Boyle W.C., (1988), "Oxygen Transfer Under Process Conditions" J. Water Pollution Control Fed., 60 (3).

Paul M. Kubera, (2001) "15,000 liter Bioreactor Gas Dispersion, Oxygen Transfer and Blending Studies" Mixing Technology Development Program, November.

Richard C. A.; Gordon B. Rattray; and Paul P. D., (1974), "Air Diffusion Unit" J. Water Pollution Control Fed., 46 (5).

Rosso D.; Iranpour, R.; Stenstrom, M.K, (2001), "Fine Pore Aeration -Fifteen Years of OffGas Transfer Efficiency Measurements", Water Environment Federation, WEFTEQ.

Shifrin S. M.; Mishukov B. G., (1972), "Treatment of Wastewater for Dairy Industry", Publishing House Stroyizdat, Moscow, (In Russian).

Suschka J., "Oxygenation in Aeration Tanks", J. Water Pollution Control Fed., 43 (1), 1971

Tzeng, Chwen-Jeng; Iranpour, Reza; Stenstrom Michael K., (2003), "Modeling and Control of Oxygen Transfer in High Purity Oxygen Activated Sludge Process", Journal of Environmental Engineering, Vol. 129, No. 5.

Warriner R.; Brenner R.C. ${ }^{1}$, (1996), "Oxygen Transfer Efficiency Surveys at the Jones Island Treatment Plants 1985-1988" Risk Reduction Engineering Laboratory, Office of research and Division, US. EPA, Cincinnati, Ohio, 45268.

Warriner R.; Brenner R.C. ${ }^{2}$, (1996), "Oxygen Transfer Efficiency Surveys at the South Shore Wastewater Treatment Plant 1985-1987" Risk Reduction Engineering Laboratory, Office of research and Division, US. EPA, Cincinnati, Ohio, 45268,.

Water Environment Federation (WEF), (1996), "Aeration" manual of Practice - MOP FD-13, ASCE Manuals and Reports on Engineering Practice No. 68. American Society of Civil Engineers. New York.

The work was carried out at the college of Engineering. University of Mosul 